\title{
Analgesic, Anti-Inflammatory, and Antiplatelet Profile of Hydrazones Containing Synthetic Molecules
}

\author{
Mohammad Asif ${ }^{1}$ and Asif Husain ${ }^{2}$ \\ ${ }^{1}$ Department of Pharmacy, GRD (PG) Institute of Management and Technology, Dehradun 248009, India \\ ${ }^{2}$ Department of Pharmaceutical Chemistry, Faculty of Pharmacy, Jamia Hamdard University, New Delhi 110062, India
}

Correspondence should be addressed to Mohammad Asif; aasif321@gmail.com

Received 24 May 2013; Revised 22 September 2013; Accepted 6 October 2013

Academic Editor: Guang-Fu Yang

Copyright ( 2013 M. Asif and A. Husain. This is an open access article distributed under the Creative Commons Attribution License, which permits unrestricted use, distribution, and reproduction in any medium, provided the original work is properly cited.

Hydrazones are present in many of the bioactive compounds with wide interest because of their diverse pharmacological applications. Hydrazones possess wide variety of biological activities such as anticonvulsant, antidepressant, analgesic, anti-inflammatory, antiplatelet, antimicrobial, anticancer, antihypertensive, anthelmintic, antidiabetic, antiparasitic, and other anticipated activities. This created an interest for researchers towards synthesized variety of hydrazone derivatives for different biological activities. Therefore many researchers have synthesized hydrazone derivatives as target structures for their biological activities. This is paper focuses on the analgesic, anti-inflammatory, and antiplatelet activities of hydrazones.

\section{Introduction}

Hydrazones constitute an important class of biologically active drug molecules which has attracted the attention of medicinal chemists due to their wide range of pharmacological properties. These compounds are being synthesized as drugs by many researchers in order to combat diseases with minimal toxicity and maximal effects. These predictions have provided a therapeutic pathway to develop new effective biologically active hydrazones. A number of hydrazone derivatives have been reported to exert notably biological activities $[1,2]$.

Hydrazones possess an azomethine $-\mathrm{NHN}=\mathrm{CH}$ group which are considered as derivatives of aldehydes and ketones in which the oxygen atom has been replaced by the $=\mathrm{NNH}_{2}$ group. Hydrazones are of wide interest because of their diverse biological applications such as anticonvulsant, antidepressant, analgesic, anti-inflammatory, antiplatelet, antimalarial, antimicrobial, antimycobacterial, anticancer, vasodilator, antiviral, anti-HIV, anthelmintic, antidiabetic, and trypanocidal activities [2-10].

The hydrazones are used as hole transporting agents in organic layer photoconductors, as quantitative analytical reagents, especially in colorimetric and fluorometric determination of metal ions [11-13]. Furthermore, some hydrazones have also been used as herbicides, insecticides, nematocides, rodenticides, and plant growth regulators as well as plasticizers and stabilizers for polymers. The metal complexes of hydrazones have potential applications as catalysts, luminescent probes, and molecular sensors $[1,14,15]$. A class of $\mathrm{N}$-arylsulfonyl hydrazones has been developed as novel inhibitors of IMP-1, a metallo- $\beta$-lactamase. As a requirement for bulky aromatic substituents on each side of the sulfonyl hydrazone backbone, these compounds may serve as efficient inhibitors of IMP-1. Molecular modeling has provided structural basis for the anti-metallo- $\beta$-lactamase activity of hydrazonone compounds [16]. A series of hydrazones were evaluated as potential inhibitors of anthrax lethal factor. There were significant differences in the types of inhibition observed with the different assays [17]. Kinetic analysis of the dipeptidyl disulfides and dipeptidyl benzoylhydrazones indicated that these inhibitors act as irreversible inhibitors of Cathepsin S, and benzoylhydrazones were shown to be potent inhibitors of Cathepsin S [18]. Hydrazones and phenyl hydrazones of different aryl aldehydes showed an effect on endogenous proteolysis in liver. It was observed 
that $p$-nitro benzaldehyde hydrazone exhibited maximum inhibitory effect [19]. The effect of hydrazones and phenyl hydrazones of simple aryl aldehydes along with their semicarbazones and thiosemicarbazones on the activity of liver alkaline and acid phosphatase [20,21].

Hydrazones are an important class of compounds for new drug development. This created an interest to researchers who have synthesized variety of hydrazone derivatives and screened them for their various biological activities. In the present study, we have made an attempt to collect analgesic, anti-inflammatory, and antiplatelet properties of hydrazone derivatives. Hydrazones are not only intermediates but also very effective organic compounds when they are used as intermediates and coupling products that can be synthesized by using the active hydrozen component of $-\mathrm{CONHN}=\mathrm{CH}-$ azomethine group. Many effective compounds, such as iproniazid and isocarboxazid, are synthesized by the reduction of hydrazide-hydrazones. Iproniazid, like INH, is used in the treatment of tuberculosis. It has also displayed an antidepressant effect, and patients appear to have a better mood during the treatment. Another clinically effective hydrazidehydrazones is nifuroxazide, which is used as an intestinal antiseptic [22-25]. Hydrazones are a class of organic compounds which possess the structure $\mathrm{R}_{1} \mathrm{R}_{2} \mathrm{C}=\mathrm{NNH}_{2}$. They are related to ketone and aldehyde in which oxygen has been replaced with $\mathrm{NNH}_{2}$ group. These azometine $-\mathrm{NHN}=\mathrm{CH}-$ protons constitute an important class of compounds for drug development. Hydrazones are formed by the reaction of hydrazine or hydrazide with aldehydes and ketones. Hydrazones are widely used in organic synthesis. Many effective compounds, such as iproniazide and isocarboxazid, are synthesized by the reduction of hydrazide-hydrazones. Another effective hydrazide-hydrazone is nifuroxazide, which is used as an intestinal antiseptic [26-30]. This review highlights analgesic, anti-inflammatory, antipyretic, and antiplatelets activities shown by hydrazones.

\section{Analgesic and Anti-Inflammatory Activites}

Nonsteroidal anti-inflammatory drugs (NSAIDs) are largely used in the treatment of pain and inflammation. Hydrazones that are dual inhibitors of both cyclooxygenase (COX) and 5-lipoxygenase (5-LO) are being studied as potential analgesic and anti-inflammatory agents in comparison to NSAIDs [31]. Nonsteroidal anti-inflammatory drugs (NSAIDs) have a wide clinical use for the treatment of inflammation, pain, rheumatoid arthritis, soft tissue and oral cavity lesions, respiratory tract infections, and fever. The two isoforms of COX are poorly distinguishable by most of the classical NSAIDs, and these agents actually inhibit COX-1 extensively, besides COX-2, leading to gastrointestinal (GI) injury, suppression of TXA2 formation, and platelet aggregation. The combination of these interactions is probably the reason for GI bleeding which is the most serious complication of these drugs. Some evidence suggests that the hydrazone moiety present in some compounds possesses a pharmacophoric character for the inhibition of COX. In fact, some evidence suggests that the hydrazone moiety present in derivative possesses a pharmacophoric character for the inhibition of COX [32]. The results showed that pyridine ring at the aryl moiety of the arylhydrazone is having good analgesic activity in comparison to mefenamic acid. Compounds possessing the 4-tolyl or 4-fluorophenyl moiety are more active than 4-bromophenyl and 4-N,N-dimethylaminophenyl. The anti-inflammatory evaluation showed that the replacement of carboxylic acid group of mefenamic acid with $\mathrm{N}$-arylhydrazone moiety cannot produce any advantage in the anti-inflammatory property [33]. Analgesic activity of some (4Z)-3-methyl-1-[(2-oxo-2Hchromene-4-yl)carbonyl]$1 \mathrm{H}$-pyrazole-4,5-dione4-(4-substitutedphenyl)hydrazone, some of them showed significant analgesic activity. Pharmacological evaluation was done by using acetic acid-induced writhing model in mice which showed that the presence of 4-chloro, 4-bromo, 3,4-dichloro, 3,4-dibromo, and 4methyl group in the aromatic ring of 4-position of the pyrazole-hydrazono nucleus gave rise to increased analgesic activities [34]. Hydrazone derivatives of quinoxalinone and evaluated for anti-inflammatory activity showed that compounds having methoxy group at the para-position showed comparatively good percentage of inhibition of edema than the other compounds [35]. Treatment of 3-cyano acetylindole with diazonium salts of 3-phenyl-5-amino pyrazole and 2-amino pyrazole gave the corresponding hydrazones. Compound 3-(1H-Indol-3-yl)-3-oxo-2-[(5-phenyl-2H-pyrazol-3-yl)-hydrazono]-propionitrile was found to possess appreciable analgesic and anti-inflammatory activity [36]. The anti-inflammatory derivative 2-(2-formylfuryl) pyridylhydrazone (1) presented a $79 \%$ inhibition of pleurisy at a dose of $80.1 \mu \mathrm{mol} / \mathrm{kg}$. The results concerning the mechanism of the action of these series of $N$-heterocyclic derivatives in platelet aggregation suggest a $\mathrm{Ca}^{2+}$ scavenger mechanism. Compound 2 was able to complex $\mathrm{Ca}^{2+}$ in in vitro experiments at $100 \mu \mathrm{M}$ concentration, indicating that these series of compounds can act as $\mathrm{Ca}^{2+}$ scavenger depending on the nature of the aryl moiety present at the imine subunit [37]. A series of analgesic compounds that belong to the $\mathrm{N}$-acylarylhydrazone class were synthesized from natural safrole. [( $4^{\prime}$-N,N-Dimethylaminobenzylidene3-(3',4' methylenedioxyphenyl)propionyl hydrazine] (2) was more potent than dipyrone and indomethacin [38]. Analgesic and anti-inflammatory activity of furoxanyl-Nacylhydrazones $(3,4)$ [39]. The anti-inflammatory activity of some aryl hydrazones (5) got good results [40]. Various hydrazone derivatives (6) reported them to have promising in vivo anti-inflammatory activity [41]. Hydrazone derivatives (7) with selective COX-2 inhibition. The compound is reported to have an $\mathrm{ED}_{50}$ value of $0.2 \mathrm{mmol} / \mathrm{Kg}$ [42]. Benzothiophene derivatives (8) with inhibition of $50.2 \%$ have been developed [43]; see Figure 1.

Fifteen different isatin[N-(2-alkylbenzoxazole-5-carbonyl)] hydrazones (9) were screened for analgesic, antidepressant, and H1-antihistaminic activities [44]. These compounds were also studied for their effect on pentobarbitoneinduced narcosis. Three compounds bearing a methyl substituent at 7-position of the benzoxazole system exhibit good analgesic activity. Schiff bases and phenyl hydrazone of isatins, prepared from isatin and appropriate aromatic primary 
<smiles>C(=N/Nc1ccccn1)\c1ccco1</smiles>

1<smiles>COc1cc(/C=N/NC(=O)/C(=C\c2ccccc2)C(=O)c2ccccc2)cc(Br)c1O</smiles>

5<smiles>CN(C)c1ccc(/C=N\NC(=O)CCc2ccc3c(c2)OCO3)cc1</smiles>

2<smiles>Cc1ccc(-c2nc(CC(=O)N/N=C\c3ccc(OCc4csc(-c5ccccc5)n4)cc3)cs2)cc1</smiles>

6<smiles></smiles>

3<smiles>O=C(C(=NNc1cc(C(F)(F)F)cc(C(F)(F)F)c1)C(=O)C(F)(F)F)c1ccc(Cl)cc1</smiles>

7<smiles>Cc1nonc1C(=O)N/N=C/c1ccc(C(C)C)cc1</smiles>

4<smiles>CC1=NN(C(=O)CBr)C(=O)/C1=N\Nc1ccc(C)cc1[N+](=O)[O-]</smiles>

8

Figure 1

amine/hydrazines were, screened for analgesic, anti-inflammatory, and antipyretic activity [45]. 1-Diphenylaminomethyl-3-(1-naphthylimino)-1,3-dihydroindol-3-one, 3-(1naphthylimino)-5-bromo-1,3-dihydroindol-2-one (10), and 1-diphenylaminomethyl-3-(4-methylphenylimino)-1,3-dihydroindol-3-one exhibited the highest analgesic, antiinflammatory, and antipyretic activity respectively. Few 6substituted-3(2H)-pyridazinone-2-acetyl-2-( $p$-substituted benzal)hydrazone derivatives exhibited analgesic and antiinflammatory agents. None of the compounds was found to show gastric ulcerogenic effect in comparison with reference NSAIDs [46]. 2-(2-Formylfuryl)pyridylhydrazone possessed anti-inflammatory activity and showed $79 \%$ inhibition of pleurisy at a dose of $80.1 \mu \mathrm{mol} / \mathrm{kg}$. The results indicated that these series of compounds can act as $\mathrm{Ca}^{2+}$ scavenger and platelet aggregation [37]; see Figure 2.

2.1. Antiplatelet Activity. The antiplatelet activity of tricyclic acylhydrazone derivatives (11) was evaluated by their ability to inhibit platelet aggregation of rabbit platelet-rich plasma induced by platelet activating factor (PAF) at $50 \mathrm{nM}$. Benzylidene-/4' -bromobenzylidene 3-OH-8- $\mathrm{CH}_{3}-6$-phenylpyrazolo[3,4-b] thieno-[2,3-d]pyridine-2-carbohydrazide was evaluated at $10 \mu \mathrm{M}$, presenting, respectively, 10.4 and $13.6 \%$ of inhibition of the PAF-induced platelet aggregation [37]. The evaluation of platelet antiaggregating profile let to the identification of a new potent prototype of antiplatelet derivative, that is, benzylidene $10 \mathrm{H}$-phenothiazine-1-carbohydrazide $\left(\mathrm{IC}_{50}=2.3 \mu \mathrm{M}\right)$, which acts in the AA pathway probably by the inhibition of platelet COX-1 enzyme. Additionally, the change in para-substituent group of acylhydrazone framework permitted to identify a hydrophilic carboxylate derivative and a hydrophobic bromo derivative as two new analgesics that are more potent than dipyrone, possessing selective peripheral or central mechanism of action [47]. The evaluation of platelet antiaggregating profile let to the identification of a new potent prototype, that is, benzylidene $10 \mathrm{H}$-phenothiazine-1-carbohydrazide $\left(\mathrm{IC}_{50}=2.3 \mu \mathrm{M}\right)(\mathbf{1 2})$, which acts in the arachidonic acid (AA) pathway probably by the inhibition of platelet COX-1 enzyme. Change in para-substituent group of acylhydrazone framework permitted to identify a hydrophilic carboxylate derivative and a hydrophobic bromo derivative as two analgesics that are more potent than dipyrone, possessing selective peripheral or central mechanism of action [48]. Hydrazones containing 5-methyl-2-benzoxazoline, the analgesic effects of 2-[2-(5-methyl-2-benzoxazoline-3-yl)acetyl]4-chloro-/4-methyl benzylidene hydrazine (13a) and (13b) 
<smiles>[R]c1nc2cc(C(=O)N/N=C3\Nc4ccccc4C3=O)ccc2o1</smiles>

9<smiles>O=C1Nc2ccc(Br)cc2/C1=N/c1cccc2ccccc12</smiles>

10

Figure 2<smiles>Cc1nn(-c2ccccc2)c2c1Cc1sc(C(=O)NN=C[Al])c(O)c1N2</smiles>

11<smiles>Cc1ccc(/C=N/NC(=O)Cn2c(=O)oc3ccccc32)cc1</smiles>

13b<smiles>CC(C)(C)c1cc(/C=N/NC(=O)c2ccc3c(c2)OCO3)cc(C(C)(C)C)c1O</smiles>

14<smiles>O=C(Cn1c(=O)oc2ccccc21)N/N=C/c1ccc(Cl)cc1</smiles>

13a<smiles>[X]c1ccc(NN2N=NC(C(=O)N/N=C\[Al])C2[M])cc1</smiles>

$\mathrm{Ar}=\mathrm{Ph}, \mathrm{X}=\mathrm{H}$

$\mathrm{Ar}=$ Pyrid $-4-\mathrm{yl}, \mathrm{X}=\mathrm{H}$

$\mathrm{Ar}=2$-Nitrofuryl, $\mathrm{X}=4-\mathrm{Cl}$

$\begin{array}{lll}15 & 16 & 17\end{array}$

Figure 3

were found to be higher than morphine and aspirin. In addition, 2-[2-(5-methyl-2-benzoxazoline-3-yl)acetyl]-4methoxy benzylidene hydrazine at $200 \mathrm{mg} / \mathrm{kg}$ dose possessed the anti-inflammatory activity [49]. $N^{\prime}$-(3,5-Di-tert-butyl4-hydroxybenzylidene)-6-nitro-1,3-benzodioxole-5-carbohydrazine (14) as an anti-inflammatory compound [50]. Antiplatelets decrease platelet aggregation and prevent the formation of thrombus. Hydrazone derivatives $(15,16,17)$ exhibited an in vitro antiplatelet activity; see Figure 3.

\section{Synthetic Approach for the Novel Hydrzonone and Its Biological Activity}

A number of organic compounds obtained by chemical synthesis as model compounds have useful analgesic, antiinflammatory, antipyretic, and antiplatelets activities. Many of hydrazonones its derivatives possess interesting biological activities, such as analgesic, anti-inflammatory, antimicrobial, and antitumor activites. The biological activity of synthesized hydrazonone derivatives was characterized and detailed study is in progress to modify the synthetic route, structural activity, and toxicological barriers for the enhanced pharmacological efficiency of synthetic hydrazones [37, 45-49].

\section{Development of New NSAIDs}

The NSAIDs preparations are among the most commonly prescribed drugs. NSAIDs are sometimes known as the aspirin-like drugs because they have an activity profile that is broadly similar to that of aspirin; that is, they all possess analgesic, anti-inflammatory, and antipyretic properties to some degree and produce characteristic side effects, including gastric intolerance and depression of blood clotting through inhibitory action on platelet function. Two closely related 
forms of the cyclooxygenase have been identified which are now known as COX-1 and COX-2. Both isoenzymes transform arachidonic acid (AA) to prostaglandins (PGs) but differ in their distribution and their physiological roles. Meanwhile, the responsible genes and their regulation have been clarified. COX-1, the predominantly constitutive form of the enzyme, is expressed throughout the body and performs a number of homeostatic functions such as maintaining normal gastric mucosa and influencing renal blood flow. Simmons also recently codiscovered COX-3 in 2002 and analyzed this new isozyme's relation which acetaminophen (paracetamol), arguably the most widely used analgesic drug in the world. The clinical ramifications and knowledge of COX isozymes are therefore rapidly expanding and could perhaps offer significant hope for future treatments of pain, inflammation, and fever [37, 45-49].

\section{Discussion}

Hydrazones, possessing an azomethine $-\mathrm{NHN}=\mathrm{CH}-$ group, constitute an important class of compounds as target structures for their biological activities. These observations guide us for the development of new hydrazones that possess varied biological activities. The literature studies on hydrazones have shown that these derivatives possess a wide variety of biological activities such as antitumor, antibacterial, antiviral, antihypertensive, anticonvulsant, anti-inflammatory, analgesic, antipyretic, antiplatelets, vasorelaxant, anticoagulant, and antiprotozoal activities. There has been considerable interest in the development of novel compounds with wide varieties of biological activities. These molecules are easily prepared and have diverse pharmacological potential. This encourages to the researchers to synthesize different new compounds bearing hydrazones with low toxicity. Differently substituted hydrazones have been developed and found to be active against different pharmacological targets. These observations have been guiding the development of new hydrazones that possess varied biological activities. Hydrazone derivatives of carbonyl compounds constitute an important class of biologically active compounds [50-57].

\section{Conclusion}

Hydrazonone nucleus exhibited immense pharmacological activities. The simple hydrazonone nucleus is present in compounds are evaluating for new products that possess some remarkable pharmacological activities, such as analgesic, anti-inflammatory, antipyretic, antiplatelet aggregation, cardiotonic, antihypertensive, analgesic, vasodilatory, antidiabetic, and anticonvulsant activites. The present review focuses on hydrazonone which possesses potential analgesic, anti-inflammatory, antipyretic, and anti-platelet aggregation activities that are new in development.

\section{References}

[1] M. Singh and N. Raghav, "Biological activities of hydrazones: a review," International Journal of Pharmacy and Pharmaceutical Sciences, vol. 3, no. 4, pp. 26-32, 2011.
[2] H. S. Seleem, G. A. El-Inany, B. A. El-Shetary, and M. A. Mousa, "The ligational behavior of a phenolic quinolyl hydrazone towards copper(II)-ions," Chemistry Central Journal, vol. 5, article 2, 2011.

[3] B. F. Abdel-Wahab, G. E. A. Awad, and F. A. Badria, "Synthesis, antimicrobial, antioxidant, anti-hemolytic and cytotoxic evaluation of new imidazole-based heterocycles," European Journal of Medicinal Chemistry, vol. 46, no. 5, pp. 1505-1511, 2011.

[4] A. S. Abu-Surrah, K. A. Abu Safieh, I. M. Ahmad et al., "New palladium(II) complexes bearing pyrazole-based Schiff base ligands: synthesis, characterization and cytotoxicity," European Journal of Medicinal Chemistry, vol. 45, no. 2, pp. 471-475, 2010.

[5] O. O. Ajani, C. A. Obafemi, O. C. Nwinyi, and D. A. Akinpelu, "Microwave assisted synthesis and antimicrobial activity of 2quinoxalinone-3-hydrazone derivatives," Bioorganic and Medicinal Chemistry, vol. 18, no. 1, pp. 214-221, 2010.

[6] M. S. Al-Said, M. S. Bashandy, S. I. Al-Qasoumi, and M. M. Ghorab, "Anti-breast cancer activity of some novel 1,2dihydropyridine, thiophene and thiazole derivatives," European Journal of Medicinal Chemistry, vol. 46, no. 1, pp. 137-141, 2011.

[7] M. A. S. Aslam, S.-U. Mahmood, M. Shahid, A. Saeed, and J. Iqbal, "Synthesis, biological assay in vitro and molecular docking studies of new Schiff base derivatives as potential urease inhibitors," European Journal of Medicinal Chemistry, vol. 46, no. 11, pp. 5473-5479, 2011.

[8] Z. Cui, Y. Li, Y. Ling et al., "New class of potent antitumor acylhydrazone derivatives containing furan," European Journal of Medicinal Chemistry, vol. 45, no. 12, pp. 5576-5584, 2010.

[9] D. Kaushik, S. A. Khan, G. Chawla, and S. Kumar, " $\mathrm{N}$-[(5chloro-3-methyl-1-phenyl-1H-pyrazol-4-yl)methylene] 2/4substituted hydrazides: synthesis and anticonvulsant activity," European Journal of Medicinal Chemistry, vol. 45, no. 9, pp. 3943-3949, 2010.

[10] M. M. Edrees, T. A. Farghaly, F. A. A. El-Hag, and M. M. Abdalla, "Antimicrobial, antitumor and $5 \alpha$-reductase inhibitor activities of some hydrazonoyl substituted pyrimidinones," European Journal of Medicinal Chemistry, vol. 45, no. 12, pp. 5702-5707, 2010.

[11] A. A. El-Sherif, "Synthesis, spectroscopic characterization and biological activity on newly synthesized copper(II) and nickel(II) complexes incorporating bidentate oxygen-nitrogen hydrazone ligands," Inorganica Chimica Acta, vol. 362, no. 14, pp. 4991-5000, 2009.

[12] G. A. Al-Hazmi and A. A. El-Asmy, "Synthesis, spectroscopy and thermal analysis of copper(II) hydrazone complexes," Journal of Coordination Chemistry, vol. 62, no. 2, pp. 337-345, 2009.

[13] Y.-L. Sang and X.-S. Lin, "Syntheses and crystal structures of two Schiff-base copper(II) complexes with antibacterial activities," Journal of Coordination Chemistry, vol. 63, no. 2, pp. 315-322, 2010.

[14] O. Pouralimardan, A.-C. Chamayou, C. Janiak, and H. Hosseini-Monfared, "Hydrazone Schiff base-manganese(II) complexes: synthesis, crystal structure and catalytic reactivity," Inorganica Chimica Acta, vol. 360, no. 5, pp. 1599-1608, 2007.

[15] C. Basu, S. Chowdhury, R. Banerjee, H. Stoeckli Evans, and S. Mukherjee, "A novel blue luminescent high-spin iron(III) complex with interlayer $\mathrm{O}-\mathrm{H}$. . .Cl bridging: synthesis, structure and spectroscopic studies," Polyhedron, vol. 26, no. 14, pp. 36173624, 2007

[16] S. Siemann, D. P. Evanoff, L. Marrone, A. J. Clarke, T. Viswanatha, and G. I. Dmitrienko, "N-arylsulfonyl hydrazones 
as inhibitors of IMP-1 metallo- $\beta$-lactamase," Antimicrobial Agents and Chemotherapy, vol. 46, no. 8, pp. 2450-2457, 2002.

[17] M. L. Hanna, T. M. Tarasow, and J. Perkins, "Mechanistic differences between in vitro assays for hydrazone-based small molecule inhibitors of anthrax lethal factor," Bioorganic Chemistry, vol. 35, no. 1, pp. 50-58, 2007.

[18] C. L. Cywi, R. A. Firestone, D. W. McNeil, C. A. Grygon, K. M. Crane, D. M. White et al., "The design of potent hydrazones and disulfides as cathepsin S inhibitors," Journal of Molecular Structure, vol. 34, pp. 9-22, 2009.

[19] N. Raghav, M. Singh, R. Kaur, S. Suman, and P. Priyanka, "Proteolytic studies in liver homogenate in presence of substituted aryl hydrazones," Asian Journal of Chemistry, vol. 23, no. 3, pp. 1409-1410, 2011.

[20] N. Raghav, M. Singh, S. Jangra, A. Rohilla, R. Kaur, and P. Malik, "In-Vitro studies of various carbonyl derivatives on liver alkaline phosphatase," Journal of Chemical and Pharmaceutical Research, vol. 2, no. 4, pp. 801-807, 2010.

[21] N. Raghav, M. Singh, S. Jangra, A. Rohilla, R. Kaur, and P. Malik, "In-Vitro studies of various carbonyl derivatives on liver acid phosphatase," International Journal of Applied Biology and Pharmaceutical Technology, vol. 1, no. 3, pp. 1011-1015, 2010.

[22] S. Eswaran, A. V. Adhikari, I. H. Chowdhury, N. K. Pal, and K. D. Thomas, "New quinoline derivatives: synthesis and investigation of antibacterial and antituberculosis properties," European Journal of Medicinal Chemistry, vol. 45, no. 8, pp. 3374-3383, 2010.

[23] S. Kumar, S. Bawai, S. Drabu, R. Kumar, and L. Machwal, "Chloroquinolinylhydrazone derivative as anticonvulsant," Acta Poloniae Pharmaceutica, vol. 67, pp. 567-563, 2010.

[24] J.-Y. Lee, K.-W. Jeong, S. Shin, J.-U. Lee, and Y. Kim, "Discovery of novel selective inhibitors of Staphylococcus aureus $\beta$-ketoacyl acyl carrier protein synthase III," European Journal of Medicinal Chemistry, vol. 47, no. 1, pp. 261-269, 2012.

[25] G. M. Maguene, J. Jakhlal, M. Ladyman et al., "Synthesis and antimycobacterial activity of a series of ferrocenyl derivatives," European Journal of Medicinal Chemistry, vol. 46, no. 1, pp. 31$38,2011$.

[26] R. M. Mohareb, K. A. El-Sharkawy, M. M. Hussein, and H. M. El-Sehrawi, "Synthesis of hydrazide-hydrazone derivatives and their evaluation of antidepressant, sedative and analgesic agents," Journal of Pharmaceutical Sciences and Research, vol. 2, no. 4, pp. 185-196, 2010.

[27] A. Özdemir, G. Turan-Zitouni, Z. Asim Kaplancikli, G. Işcan, S. Khan, and F. Demirci, "Synthesis and the selective antifungal activity of 5,6,7,8-tetrahydroimidazo[1,2-a]pyridine derivatives," European Journal of Medicinal Chemistry, vol. 45, no. 5, pp. 2080-2084, 2010.

[28] R. N. Sharma, K. P. Sharma, and S. N. Dikshit, "Synthesis, characterization and biological activities of some new hypophosphorousadducts of acid hydrazones derived from 2[(N-benzoyl) 2, 3-dichloroanilido] acetohydrazide," Archives of Applied Science Research, vol. 3, pp. 415-424, 2011.

[29] S. M. Siddiqui, A. Salahuddin, and A. Azam, "Synthesis, characterization and antiamoebic activity of some hydrazone and azole derivatives bearing pyridyl moiety as a promising heterocyclic scaffold," European Journal of Medicinal Chemistry, vol. 49, pp. 411-416, 2012.

[30] E. A. Musad, R. Mohamed, B. Ali Saeed, B. S. Vishwanath, and K. M. Lokanatha Rai, "Synthesis and evaluation of antioxidant and antibacterial activities of new substituted bis(1,3,4oxadiazoles), 3,5-bis(substituted) pyrazoles and isoxazoles,"
Bioorganic and Medicinal Chemistry Letters, vol. 21, no. 12, pp. 3536-3540, 2011.

[31] A. Almasirad, M. Tajik, D. Bakhtiari et al., "Synthesis and analgesic activity of $\mathrm{N}$-arylhydrazone derivatives of mefenamic acid," Journal of Pharmacy and Pharmaceutical Sciences, vol. 8, no. 3, pp. 419-425, 2005.

[32] R. Kalsi, M. Shrimali, T. N. Bhalla, and J. P. Barthwal, "Synthesis and anti-inflammatory activity of indolyl azetidinones," Indian Journal of Pharmaceutical Sciences, vol. 41, pp. 353-359, 2006.

[33] A. Almasirad, M. Tajik, D. Bakhtiari et al., "Synthesis and analgesic activity of $\mathrm{N}$-aryl hydrazone derivatives of mefenmic acid," Journal of Pharmaceutical Sciences, vol. 8, no. 3, pp. 419425, 2005.

[34] K. K. Sivakumar, A. Rajasekaran, I. Ponnilavarasan, A. Somasundaram, R. Sivasakthi, and S. Kamalaveni, "Antimicrobial and analgesic activity of some (4Z)-3-methyl-1-[(2oxo-2H-chromen-4-yl)carbonyl]-1H-pyrzole-4, 5-dione 4-[(4substitutedphenyl) hydrazone]," Scholars Research Library, vol. 2, no. 1, pp. 211-219, 2010.

[35] S. A. Khan, P. Mullick, S. Pandit, and D. Kaushik, "Synthesis of hydrazones derivatives of quinoxalinone-prospective antimicrobial and antiinflammatory agents," Acta Poloniae Pharmaceutica, vol. 66, no. 2, pp. 169-172, 2009.

[36] M. A. A. Radwan, E. A. Ragab, N. M. Sabry, and S. M. El-Shenawy, "Synthesis and biological evaluation of new 3substituted indole derivatives as potential anti-inflammatory and analgesic agents," Bioorganic and Medicinal Chemistry, vol. 15, no. 11, pp. 3832-3841, 2007.

[37] A. R. Todeschini, A. L. P. De Miranda, K. C. M. Da Silva, S. C. Parrini, and E. J. Barreiro, "Synthesis and evaluation of analgesic, antiinflammatory and antiplatelet properties of new 2-pyridylarylhydrazone derivatives," European Journal of Medicinal Chemistry, vol. 33, no. 3, pp. 189-199, 1998.

[38] P. C. Lima, L. M. Lima, K. C. M. Da Silva et al., "Synthesis and analgesic activity of novel $\mathrm{N}$-acylarylhydrazones and isosters, derived from natural safrole," European Journal of Medicinal Chemistry, vol. 35, no. 2, pp. 187-203, 2000.

[39] P. Hernández, M. Cabrera, M. L. Lavaggi et al., "Discovery of new orally effective analgesic and anti-inflammatory hybrid furoxanyl N-acylhydrazone derivatives," Bioorganic and Medicinal Chemistry, vol. 20, no. 6, pp. 2158-2171, 2012.

[40] G. Rajitha, N. Saideepa, and P. Praneetha, "Synthesis and evaluation of $\mathrm{N}$-( $\alpha$-benzamido cinnamoyl) aryl hydrazone derivatives for anti-inflammatory and antioxidant activities," Indian Journal of Chemistry B, vol. 50, no. 5, pp. 729-733, 2011.

[41] C. M. Moldovan, O. Oniga, A. Pârvu et al., "Synthesis and antiinflammatory evaluation of some new acyl-hydrazones bearing 2-aryl-thiazole," European Journal of Medicinal Chemistry, vol. 46, no. 2, pp. 526-534, 2011.

[42] M. A.-A. El-Sayed, N. I. Abdel-Aziz, A. A.-M. Abdel-Aziz, A. S. El-Azab, Y. A. Asiri, and K. E. H. Eltahir, "Design, synthesis, and biological evaluation of substituted hydrazone and pyrazole derivatives as selective COX-2 inhibitors: molecular docking study," Bioorganic and Medicinal Chemistry, vol. 19, no. 11, pp. 3416-3424, 2011.

[43] A. M. Isloor, B. Kalluraya, and K. Sridhar Pai, "Synthesis, characterization and biological activities of some new benzo[b]thiophene derivatives," European Journal of Medicinal Chemistry, vol. 45, no. 2, pp. 825-830, 2010.

[44] M. Sarangapani and V. M. Reddy, "Pharmacological screening of isatin-[N-(2-alkylbenzoxazole-5-carbonyl)] hydrazones," 
Indian Journal of Pharmaceutical Sciences, vol. 59, no. 3, pp. 105109, 1997.

[45] S. K. Sridhar and A. Ramesh, "Synthesis and pharmacological activities of hydrazones, schiff and mannich bases of isatin derivatives," Biological and Pharmaceutical Bulletin, vol. 24, no. 10, pp. 1149-1152, 2001.

[46] M. Gökçe, S. Utku, and E. Küpeli, "Synthesis and analgesic and anti-inflammatory activities 6-substituted-3(2H)-pyridazinone-2-acetyl-2-(p-substituted/nonsubstituted benzal) hydrazone derivatives," European Journal of Medicinal Chemistry, vol. 44, no. 9, pp. 3760-3764, 2009.

[47] A. G. M. Fraga, C. R. Rodrigues, A. L. P. De Miranda, E. J. Barreiro, and C. A. M. Fraga, "Synthesis and pharmacological evaluation of novel heterotricyclic acylhydrazone derivatives, designed as PAF antagonists," European Journal of Pharmaceutical Sciences, vol. 11, no. 4, pp. 285-290, 2000.

[48] G. A. Silva, L. M. M. Costa, F. C. F. Brito, A. L. P. Miranda, E. J. Barreiro, and C. A. M. Fraga, "New class of potent antinociceptive and antiplatelet $10 \mathrm{H}$-phenothiazine-1-acylhydrazone derivatives," Bioorganic and Medicinal Chemistry, vol. 12, no. 12, pp. 3149-3158, 2004.

[49] U. Salgin-Gökşen, N. Gökhan-Kelekçi, Ö. Göktaş et al., "1Acylthiosemicarbazides, 1,2,4-triazole-5(4H)-thiones, 1,3,4-thiadiazoles and hydrazones containing 5-methyl-2-benzoxazolinones: synthesis, analgesic-anti-inflammatory and antimicrobial activities," Bioorganic and Medicinal Chemistry, vol. 15, no. 17, pp. 5738-5751, 2007.

[50] C. D. Duarte, J. L. M. Tributino, D. I. Lacerda et al., "Synthesis, pharmacological evaluation and electrochemical studies of novel 6-nitro-3,4-methylenedioxyphenyl-N-acylhydrazone derivatives: discovery of LASSBio-881, a new ligand of cannabinoid receptors," Bioorganic and Medicinal Chemistry, vol. 15, no. 6, pp. 2421-2433, 2007.

[51] A. Deep, S. Jain, P. C. Sharma, P. Verma, M. Kumar, and C. P. Dora, "Design and biological evaluation of biphenyl-4carboxylic acid hydrazide-hydrazone for antimicrobial activity," Acta Poloniae Pharmaceutica, vol. 67, no. 3, pp. 255-259, 2010.

[52] B. Durgun, G. Capan, N. Ergenc, and S. Rollas, "Synthesis, characterization and biological evaluation of new benzylidenebenzohydrazides and 2,5-disubstituted-2,3-dihydro-1,3,4oxadiazoles," Pharmazie, vol. 48, no. 12, pp. 942-943, 1993.

[53] O. I. El-Sabbagh, M. A. Shabaan, H. H. Kadry, and E. S. Al-Din, "New octahydroquinazoline derivatives: synthesis and hypotensive activity," European Journal of Medicinal Chemistry, vol. 45, no. 11, pp. 5390-5396, 2010.

[54] J. L. Gage, R. Onrust, D. Johnston et al., "N-Acylhydrazones as inhibitors of PDE10A," Bioorganic and Medicinal Chemistry Letters, vol. 21, no. 14, pp. 4155-4159, 2011.

[55] F. Hayat, A. Salahuddin, J. Zargan, and A. Azam, "Synthesis, characterization, antiamoebic activity and cytotoxicity of novel 2-(quinolin-8-yloxy) acetohydrazones and their cyclized products (1,2,3-thiadiazole and 1,2,3-selenadiazole derivatives)," European Journal of Medicinal Chemistry, vol. 45, no. 12, pp. 6127-6134, 2010.

[56] Y. Jin, Z. Tan, M. He et al., "SAR and molecular mechanism study of novel acylhydrazone compounds targeting HIV-1 CA," Bioorganic and Medicinal Chemistry, vol. 18, no. 6, pp. 21352140, 2010.

[57] S. Rollas and Ş. G. Küçükgüzel, "Biological activities of hydrazone derivatives," Molecules, vol. 12, no. 8, pp. 1910-1939, 2007. 

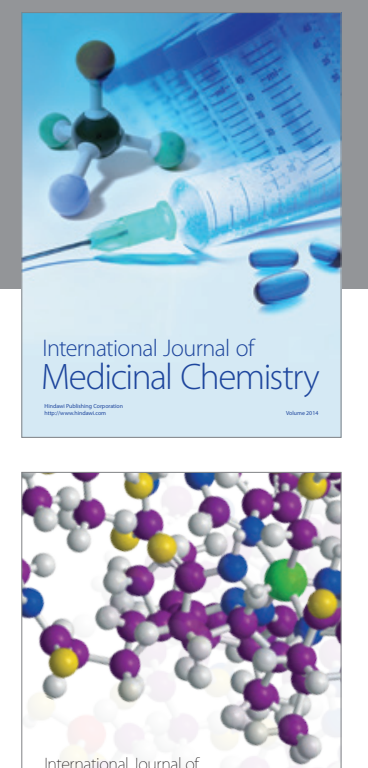

\section{Carbohydrate} Chemistry

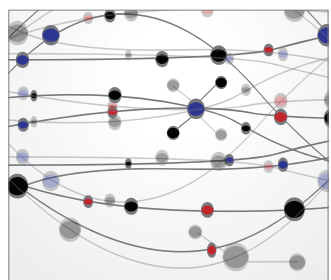

The Scientific World Journal
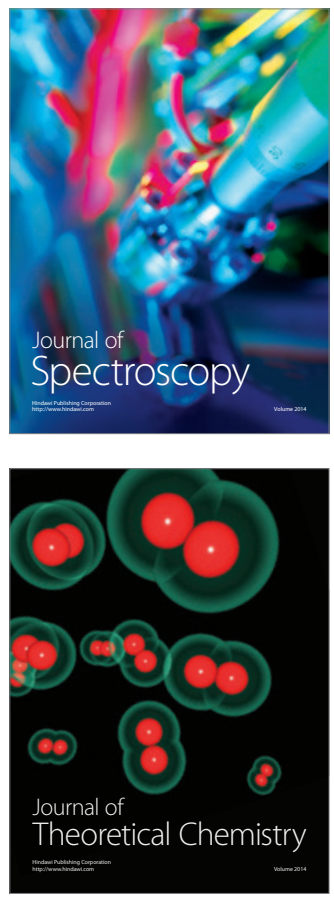
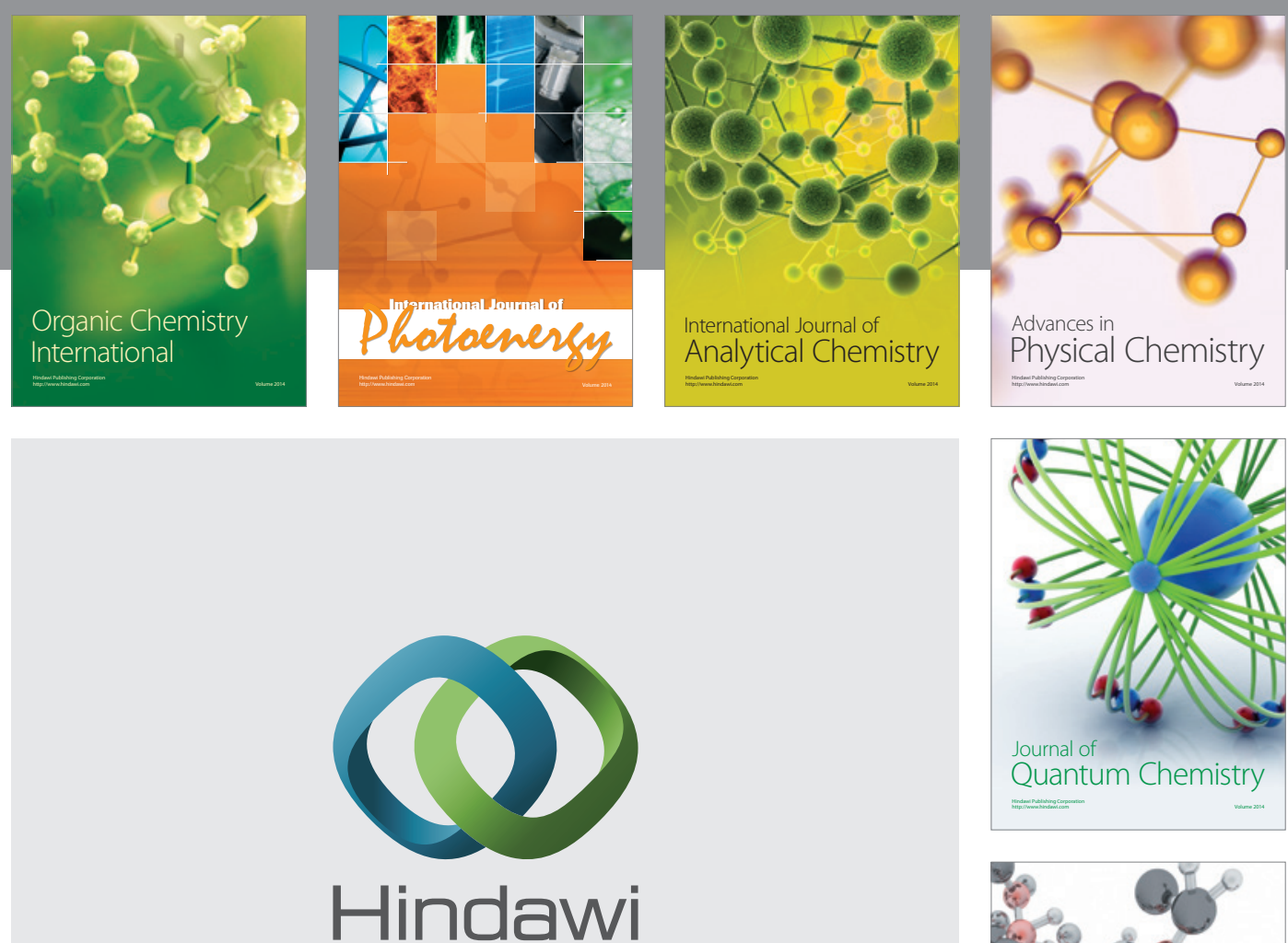

Submit your manuscripts at

http://www.hindawi.com

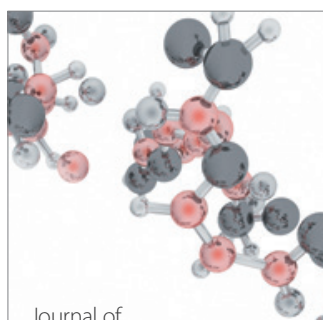

Analytical Methods

in Chemistry

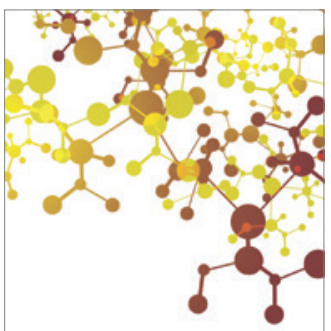

Journal of

Applied Chemistry

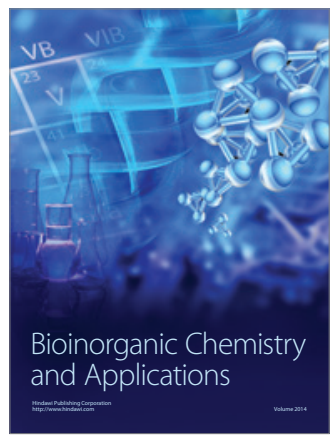

Inorganic Chemistry
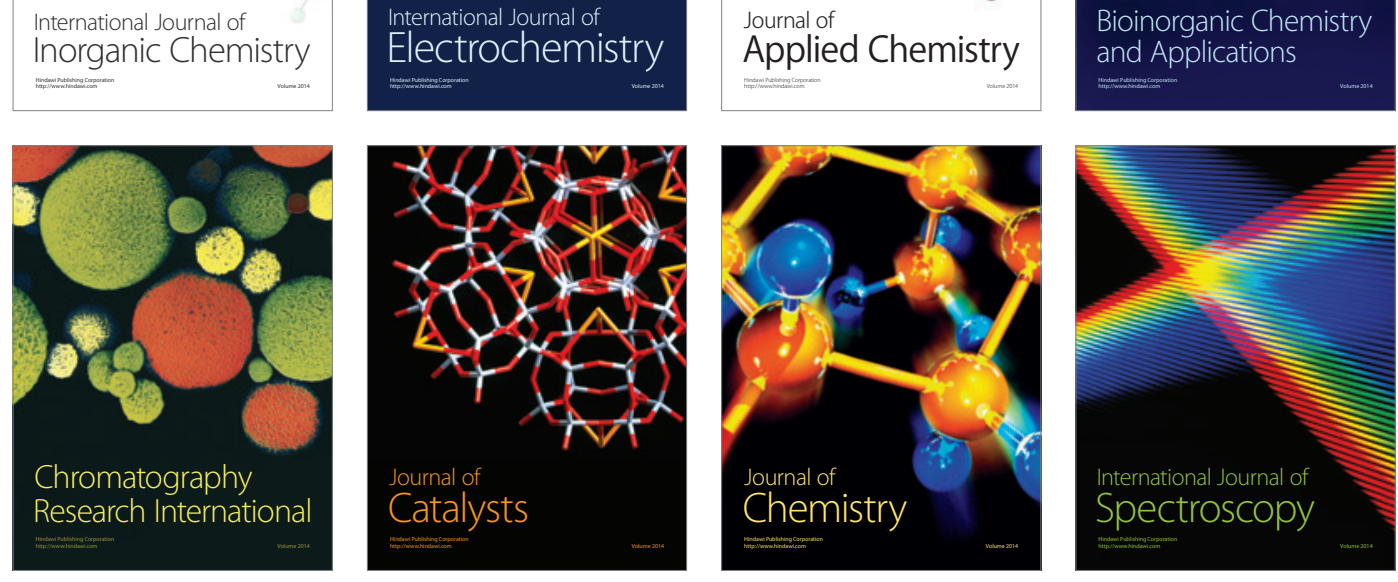